\title{
What Goliaths and Davids among Swiss firms tell us about expected returns on Swiss asset markets
}

\author{
David R. Haab ${ }^{1}$ and Thomas Nitschka²* (D)
}

\begin{abstract}
Motivated by recent US evidence, we evaluate the predictive power of changes in the weight of large firms in the aggregate stock market ("Goliath vs David" (GVD)) for Swiss stock market returns and bond market returns. Previous research suggests that the asset return dynamics in the US and Switzerland differ markedly. Forecasting Swiss asset returns hence constitutes a challenging "out-of-sample" test for GVD. Over the sample period from January 1999 to December 2017, we find that the Swiss version of GVD exhibits predictive power for Swiss stock and bond market returns even in the presence of global predictors. However, Swiss bond market returns are best predicted by the US term spread.
\end{abstract}

Keywords: Bond market, predictability, Risk premium, Stock market

JEL: G15, G17

\section{Introduction}

This paper examines a recently proposed predictor of the US bond and stock returns in a different country-specific context. Such international assessments help to shed light on the issue of whether conclusions drawn from empirical studies based on US data hold for other economies as well. For example, Cochrane (2008) shows that the US dividend-price ratio predicts US stock market returns but does not forecast dividends. However, international evidence provided by Engsted and Pedersen (2010) or Rangvid et al. (2014) suggests that dividend-price ratios predict dividend growth in various countries.

Our paper focuses on an intuitive predictor of asset returns and the state of the economy proposed by Duarte and Kapadia (2017). Changes of large firms' stock market capitalization relative to the changes in the aggregate stock market capitalization, "Goliath versus David" or GVD, forecast US stock and bond returns as well as macroeconomic variables. To the best of our knowledge, the in-sample and out-of-sample forecast ability for stock returns and bond returns makes it unique among

*Correspondence: thomas.nitschka@snb.ch

2 Swiss National Bank, Börsenstrasse 15, 8022 Zürich, Switzerland

Full list of author information is available at the end of the article predictors of US asset returns (Duarte and Kapadia 2017; Goyal and Welch 2008).

Swiss asset markets provide an ideal "out-of-sample" test case for the predictive power of GVD. Rey (2004) and Nitschka (2014) highlight that the time variation in excess returns on both Swiss stock and Swiss bond markets predominantly reflects cash-flow news, i.e., dividend news in the case of stock market returns and long-term inflation news in the case of government bond returns. In this respect, Swiss stock markets appear to be representative of other European stock markets (Nitschka 2010). By contrast, time variation in the returns on the US stock and bond markets is primarily driven by discountrate/expected-return news (Campbell 1991; Campbell and Ammer 1993; Campbell and Vuolteenaho 2004). Duarte and Kapadia (2017) highlight that GVD is supposed to capture variation in discount rates. Against this background, it is not clear whether we can expect a Swiss version of GVD to predict returns on Swiss asset markets at all because cash-flow news appear to dominate their variation.

Moreover, we have access to data at the individual stock level for all stocks that have ever been electronically traded on the Swiss stock exchange. This information 
allows us to construct Swiss versions of GVD with data that matches the quality of the US data. To the best of our knowledge, our stock-level data is extraordinarily detailed compared with stock market data of other small, open economies. However, since electronic trading started only at the end of the 1990s, our empirical assessments of return predictability are restricted to the sample period from January 1999 to December 2017.

We analyze the predictive power of a Swiss version of GVD for Swiss stock and bond markets. Similar to the US evidence, we find that a Swiss version of GVD forecasts Swiss stock market returns at time horizons of 6 to 12 months in- and out-of-sample. Even though the outof-sample evidence is by far less pronounced than the in-sample evidence, our findings are qualitatively similar to the US evidence of this variable's forecast power (Duarte and Kapadia 2017). However, we find that the distinction between the two components of GVD matters for its ability to forecast Swiss stock market returns. This is not the case in the US. ${ }^{1}$ GVD ${ }^{\text {new }}$ (differences in net new equity issuances between large firms and the aggregate market) dominates variation in Swiss GVD. It is this component that exhibits the in-sample predictive power for Swiss stock market returns. GVD old (differences in the returns on existing capital between large firms and the aggregate market) exhibits some forecast ability for Swiss bond market returns, but its predictive power is by far less pronounced than for its US counterpart.

Since financial markets are globally intertwined, we additionally evaluate whether the Swiss version of GVD adds additional predictive power for Swiss stock market returns in the presence of global (US) predictors of national stock market returns. Our results suggest that the US dividend yield is the best global predictor of Swiss stock market returns in our sample period. However, the predictive power of the Swiss GVD ${ }^{\text {new }}$ survives in the presence of the US dividend yield. On Swiss bond markets, the US term spread predicts Swiss government bond returns in-sample as well as out-of-sample and thus outperforms the Swiss GVD ${ }^{\text {old }}$.

Lastly, we evaluate whether our findings have an impact on one of our motivations to examine a Swiss version of GVD, namely the different characteristics of Swiss and US asset return dynamics, i.e, whether cash-flow or discountrate news dominate the time variation in asset returns. Our results suggest that the general conclusions from earlier studies (Rey 2004; Nitschka 2014) qualitatively still hold. However, once we additionally take the US dividend yield and the US term spread explicitly into account, we attribute more of the variation in unexpected Swiss stock market returns to discount-rate news than in the earlier studies.

The remainder of the paper is organized as follows. Section 2 describes the data and their sources. Section 3 presents the baseline empirical results. Section 4 assesses the implications of our main findings for decompositions of asset returns into news components. Finally, Section 5 concludes. The Appendix provides additional results and robustness checks.

\section{Asset return predictability: data and descriptive statistics}

This paper assesses the predictability of Swiss asset returns over the sample period from January 1999 to December 2017. This sample period is restricted by the availability of data to construct GVD, the predictive variable that is the focus of our study. The data frequency is monthly.

\subsection{Dependent variables}

This paper examines whether excess returns on Swiss stock and bond market indices are predictable. Excess returns are defined as log return on the Swiss stock or bond index, $r_{t+1}=\ln \left(\frac{P_{t+1}}{P_{t}}\right)$, in excess of the risk-free rate, which we approximate by the 1-month Swiss franc (CHF) LIBOR rate. The source of the LIBOR rate is the Swiss National Bank (SNB).

As a proxy of the Swiss stock market index, we use the MSCI Swiss total return index denominated in CHF. Total return indices assume that dividends are reinvested in the index. MSCI indices are widely used in academic studies and are publicly available on the MSCI website.

As a proxy of the Swiss bond market index, we use the Citigroup World Bond Index Switzerland which is constructed under the assumption that coupon payments are reinvested in the index. In addition, it aggregates bonds across maturities. The source of this data is Thompson Reuters Datastream.

\subsection{GVD}

Using stock-level data on the information about different components of changes in a stock's market capitalization, we compile a Swiss version of a recently proposed predictor of the US asset returns and the state of the economy (Duarte and Kapadia 2017). Duarte and Kapadia (2017) argue that changes in large firms' stock market capitalization relative to the changes in the aggregate stock market capitalization ("Goliath versus David" or GVD) are a natural candidate as a predictor of asset returns. When the market capitalization of small firms falls relative to the market capitalization of the big firms, i.e., GVD increases, then this movement signals a bad economic state. This interpretation is based on work by Bernanke and Gertler (1989); Gertler and Gilchrist (1994); Kiyotaki and Moore (1997). These authors argue that small firms are more sensitive to the business cycle. Moreover, there is evidence that small US firms' stocks exhibit greater variation in expected returns than large firms' stocks during 
expansions and recessions (Perez-Quiros and Timmermann 2000). In addition, changes in the market capitalization of large firms in the form of issuances of new equity might be less sensitive to the business cycle than equity issuances of small firms. Covas and Den Haan (2011) find equity issuances of small firms to be more pro-cyclical than equity issuances of large firms in a sample of US firms.

We follow Duarte and Kapadia (2017) and define GVD as change in the weight of the $L$ largest firms in the aggregate Swiss stock market from $t-\Delta t$ to $t$. Hence, GVD basically measures the total return of the $L$ largest firms relative to the total return on the market portfolio. This return difference can be decomposed into components that reflect the relative returns on existing capital, i.e., the relative ex-dividend returns $\left(R_{t, \Delta t}^{\mathrm{ex}}\right)$, and the relative growth rates due to the raising of (net) new capital $\left(\mathrm{NNC}_{t, \Delta t}\right)$

$$
\mathrm{GVD}_{t, \Delta t}^{L}=\left(R_{t, \Delta t}^{\mathrm{ex}, L}-R_{t, \Delta t}^{\mathrm{ex}, M}\right)+\left(\mathrm{NNC}_{t, \Delta t}^{L}-\mathrm{NNC}_{t, \Delta t}^{M}\right)
$$

The first term on the right-hand side of Eq. (1), $\left(R_{t, \Delta t}^{\mathrm{ex}, L}-\right.$ $R_{t, \Delta t}^{\mathrm{ex}, M}$ ), measures the changes in the prices of existing capital of the $L$ largest firms relative to the $M$ firms that form the market portfolio. The second term on the right-hand side of Eq. (1), $\left(\mathrm{NNC}_{t, \Delta t}^{L}-\mathrm{NNC}_{t, \Delta t}^{M}\right)$, measures changes in the market capitalization of the $L$ largest firms due to capital raising or capital decreasing activities relative to the $M$ firms that form the market portfolio.

NNC reflects the difference between corporate actions that increase and decrease market capitalization. Measures that increase the market capitalization are the issuance of new shares or new listings. Measures that decrease the market capitalization are delistings of firms or share buybacks and dividend payments.

As in Duarte and Kapadia (2017), we use the following abbreviations $\mathrm{GVD}_{t, \Delta t}^{L, \text { old }}=\left(R_{t, \Delta t}^{\mathrm{ex}, L}-R_{t, \Delta t}^{\mathrm{ex}, M}\right)$ and $\mathrm{GVD}_{t, \Delta t}^{L \text {, new }}=$ $\left(\mathrm{NNC}_{t, \Delta t}^{L}-\mathrm{NNC}_{t, \Delta t}^{M}\right)$, such that

$$
\mathrm{GVD}_{t, \Delta t}^{L}=\mathrm{GVD}_{t, \Delta t}^{L, \text { old }}+\mathrm{GVD}_{t, \Delta t}^{L, \text { new }}
$$

Our main empirical results are obtained for $L=50$. We also follow Duarte and Kapadia (2017) and set $\Delta t$ to 12 months in the baseline specification of GVD.

The choice of $L=50$ as baseline case appears to be relatively high because these firms capture approximately $90 \%$ of the total market capitalization of all publicly traded shares as we highlight in the Appendix. We opted for a relatively high number of firms to be included in the bucket of large companies in order to increase the range of industrial sectors in the computation of GVD. This limits the influence of few, big firms on time variation in GVD and thus on the empirical results. Three companies ${ }^{2}$ make up between $40 \%$ and $50 \%$ of the total Swiss stock market capitalization in our sample period. Hence, the lower $L$, the higher the influence of these three firms on GVD and thus on the empirical results. We provide robustness checks (varying $L$ ) in the Appendix to illustrate this point.

Panel A of Table (1) presents some descriptive statistics of GVD and its two components. The negative average value of GVD indicates that the market capitalization of the large firms grew less than the market capitalization of the smaller firms. This finding appears to be mainly driven by the evolution of net new capital because the average value of GVD ${ }^{\text {new }}$ explains most of the average value of GVD. The autocorrelation of GVD is relatively high with an autocorrelation coefficient of approximately 0.9 .

To get a sense of the main driver of the variation in total GVD ( $L=50$ and setting $\Delta t$ to 12 months), we perform a variance decomposition of the following form

$$
\begin{aligned}
\operatorname{var}(G V D)= & \operatorname{var}\left(G V D^{\text {old }}\right)+\operatorname{var}\left(G V D^{\text {new }}\right) \\
& +2 \operatorname{cov}\left(G V D^{\text {old }}, G V D^{\text {new }}\right)
\end{aligned}
$$

and

$$
1=\frac{\operatorname{var}\left(G V D^{\text {old }}\right)}{\operatorname{var}(\mathrm{GVD})}+\frac{\operatorname{var}\left(G V D^{\text {new }}\right)}{\operatorname{var}(\mathrm{GVD})}+2 \frac{\operatorname{cov}\left(G V D^{\text {old }}, G V D^{\text {new }}\right)}{\operatorname{var}(\mathrm{GVD})}
$$

The results of this decomposition are displayed in panel B of Table 1 and show that approximately $80 \%$ of the variation in GVD is driven by $G V D^{\text {new }}$, i.e., changes in net new capital of large firms relative to changes in net new capital of the total Swiss stock market. The differences in the relative valuation of large and small firms in the Swiss stock market are hence primarily driven by differences in net new capital between large firms and the aggregate market. The correlation between the two components of GVD, GVD ${ }^{\text {new }}$ and $G D^{\text {old }}$, is close to zero (correlation coefficient - 0.03).

\subsection{US predictors: data and correlation with Swiss GVD}

We assess whether GVD exhibits predictive power for Swiss asset market returns and compare it with the standard US predictors of stock and bond market returns. This comparison assumes that the US variables are a stand-in for global predictors of asset returns. We use the CRSP database to update the US version of GVD (GVD US $)$ based on the original data graciously provided to us by 
Table 1 Descriptive statistics and variance decomposition: GVD and its components

\begin{tabular}{llllll}
\hline \multicolumn{2}{c}{ Panel A: Descriptive statistics } & & & & Min \\
Mean & Std Dev & Max & -0.156 & Auto correlation \\
GVD & -0.195 & 0.030 & 0.051 & -0.130 & 0.880 \\
GVD new & -0.173 & 0.027 & 0.035 & -0.045 & 0.838 \\
GVD & -0.022 & 0.013 & 0.055 & 0.906
\end{tabular}

Panel B: Variance decomposition

\begin{tabular}{|c|c|c|c|}
\hline & $\frac{\operatorname{var}\left(G V D^{o l d}\right)}{\operatorname{var}(G V D)}$ & $\frac{\operatorname{var}\left(G \mathrm{GVD} \mathrm{Dew}^{\mathrm{n}}\right)}{\operatorname{var}(\mathrm{GVD})}$ & $2 \frac{\operatorname{cov}\left(G V D^{o l d}, G V D^{\text {new }}\right)}{\operatorname{Var}(G V D)}$ \\
\hline Share explained & 0.205 & 0.828 & -0.033 \\
\hline
\end{tabular}

Notes: Panel A of this table presents descriptive statistics of GVD which is defined as the change in the weight of the $L$ largest firms in the aggregate Swiss stock market from $t-\Delta t$ to $t$. Here, $\Delta t$ is 12 months and $L=50$. GVD old measures that component of GVD that is due to changes in the prices of existing capital of the $L$ largest firms relative to the aggregate market from $t-12$ to $t$. GVD new measures that component of GVD that is due to changes in the market capitalization of the $L$ largest firms relative to the aggregate market from $t-12$ to $t$ due to capital raising or capital decreasing activities such as the issuance of new shares or share buybacks. Panel B presents the variance decomposition of GVD into the parts driven by GVD old,$G V D^{\text {new }}$, and the covariance between GVD old and GVD new. The sample period runs from January 1999 to December 2017

Nishad Kapadia. In addition, our assessment uses the Goyal and Welch (2008) dataset of standard US predictors of asset returns. These data are freely available on Amit Goyal's website. We examine the forecast ability of the predictive variables for which data at the monthly frequency is available. These variables include different variants of ratios of dividends or earnings and prices of the S\&P 500 index. These ratios are the dividend-price ratio $(d p)$, the dividend yield $(d y)$, the earnings-price ratio $(e p)$, and the dividend payout ratio, which is defined as the difference between the log of dividends and the log of earnings $(d e)$. In addition, we assess the predictive power of stock market variance (svar), the net equity expansion (ntis), and two interest rate variables, i.e., the term spread $(t s)$ and the default spread $(d s)$. The stock market variance is the sum of squared daily returns on the S\&P 500 . Net equity expansion is the 12-month moving sum of net equity issues divided by the total market capitalization of stocks traded at the NYSE. Since our analysis is based on a shorter sample period than the analysis of Goyal and Welch (2008), we differ in the definition of interest rate-based predictors and define the term spread as the difference between a 10-year US government bond yield and the 1-month treasury bill rate. The default spread is the difference between yields on Baa-rated corporate bonds and the 10 -year government bond yield. For a more detailed description of the data, we kindly refer the reader to Goyal and Welch (2008).

Table 2 displays the pairwise correlation coefficients between the components of Swiss GVD and the US predictors. The Swiss GVD components exhibit the strongest correlations with the dividend-price ratio, the dividend yield, and the term spread. The correlation coefficients with these variables range from approximately 0.3 to 0.5 . The correlations with the US version of GVD are low. They range between 0.07 and 0.14 .

\section{Predicting stock and bond market returns}

This section presents our baseline results. We start with the results from our assessments of in-sample predictability of Swiss stock and bond market returns. The second subsection provides the corresponding out-of-sample forecast results.

\subsection{In-sample predictability}

Our in-sample predictability assessments are based on OLS regressions of log returns measured from $t$ to $t+h$ in excess of the risk-free rate on the predictive variables presented in Section 2. The regression has the following form

$$
r_{t, t+h}^{\text {stock,bond }}=\alpha+\beta^{h} x_{t}+\varepsilon_{t, t+h}
$$

in which the log excess return for time horizon $t+h$ is the sum of $\log$ one-period excess returns from $t$ to $t+h$ and $x$ denotes one of the predictors. The forecast horizons, $h$, that we consider are 1 month, 3 months, 6 months, and 12 months.

The combination of long-horizon regressions over a relatively short sample period from January 1999 to December 2017 with overlapping returns and predictors that exhibit high autocorrelations leads to a number of wellknown econometric issues that will affect the inference from this regression (Ang and Bekaert 2007; Boudoukh et al. 2008; Ferson et al. 2003; Hodrick 1992; Stambaugh 1999). To mitigate these issues, we use a wild bootstrap to compute test statistics. We follow Rapach et al. (2016) and compute heteroskedasticity and autocorrelation robust $t$ statistics from a wild bootstrap procedure that tests the null hypothesis of $\hat{\beta}^{h}=0$ against the alternative that $\hat{\beta}^{h}>0$ or $\hat{\beta}^{h}<0$ depending on the theoretical relation between the regressors and expected asset returns. ${ }^{3}$ This one-sided test procedure follows the recommendation by Inoue and Kilian (2005). Following Rapach et al. (2016), we standardize all predictors to have a standard deviation of 
Table 2 Pairwise correlations of CH GVD components with the US asset return predictors

\begin{tabular}{|c|c|c|c|c|c|c|c|c|c|c|c|}
\hline & $d p$ & $d y$ & $e p$ & de & svar & ntis & ts & ds & $G V D_{250}^{U S}$ & GVD new & GVD old \\
\hline$d p$ & 1 & & & & & & & & & & \\
\hline$d y$ & 0.98 & 1 & & & & & & & & & \\
\hline$e p$ & -0.05 & -0.05 & 1 & & & & & & & & \\
\hline de & 0.51 & 0.50 & -0.89 & 1 & & & & & & & \\
\hline svar & 0.30 & 0.22 & -0.28 & 0.38 & 1 & & & & & & \\
\hline ntis & -0.56 & -0.55 & 0.07 & -0.32 & -0.26 & 1 & & & & & \\
\hline ts & 0.36 & 0.36 & -0.22 & 0.46 & 0.16 & 0.20 & 1 & & & & \\
\hline$d s$ & 0.68 & 0.60 & -0.52 & 0.74 & 0.62 & -0.45 & 0.32 & 1 & & & \\
\hline$G V D_{250}^{U S}$ & 0.43 & 0.43 & -0.07 & 0.25 & 0.10 & -0.51 & -0.13 & 0.31 & 1 & & \\
\hline GVD new & 0.46 & 0.48 & 0.16 & 0.08 & -0.05 & -0.12 & 0.32 & 0.08 & 0.07 & 1 & \\
\hline GVD old & 0.31 & 0.28 & -0.13 & 0.26 & 0.18 & -0.07 & 0.35 & 0.36 & 0.14 & -0.03 & 1 \\
\hline
\end{tabular}

Notes: This table gives the pairwise correlations between the US predictors under study and the two components of GVD. The US variables are the dividend-price ratio ( $d p$ ), the dividend yield $(d y)$, the earnings-price ratio (ep), the dividend payout ratio (de), the stock market variance (svar), the net equity expansion (ntis), and two interest rate variables, i.e., the term spread ( $t s)$ and the default spread (ds). Moreover, we computed a US version of GVD $(G V D 250)$. The sample period runs from January 1999 to December 2017

one to assess the relative importance of the different predictors. The $p$ values of the $t$-statistics were obtained after 1000 bootstrap draws. Varying the number of draws from 1000 to 10000 has no material impact on the test statistics.

\subsubsection{US GVD and the predictability of US and Swiss stock market returns over different sample periods}

In order to construct a Swiss version of GVD, we rely on data that is only available over a relatively short sample period. This observation immediately leads to two questions. First, is there any evidence suggesting that GVD could predict Swiss asset returns in such a short sample period at all? Second, do we need to construct a Swiss version of GVD? Given the international integration of stock markets, the original US version of GVD might provide a better prediction of Swiss asset market returns and it is available for a longer sample period.

We address these two questions by running forecast regressions of the US and Swiss stock market returns on US GVD for different starting dates of the (in-sample) forecast sample period. Panel A of Table 3 summarizes the outcome of these regressions. Keeping the end date of the sample fixed at December 2017, we find that the forecast ability of the US GVD for US stock market returns deteriorates somewhat with the shrinking sample period. However, even over the sample period from January 1999 to December 2017, there is some evidence of GVD's predictive ability for future US stock market returns. Hence, assessing the predictive power of a Swiss version of GVD for Swiss asset returns is not a hopeless task.

Related to the point above and the correlation coefficients presented in Section 2.3, panel B of Table 3 shows that the US GVD does not forecast Swiss stock market returns irrespective of the sample period. This finding further motivates an assessment of the predictive ability of a Swiss version of GVD.

\subsubsection{Swiss GVD and its components}

This section presents the baseline results. It displays the main findings from evaluating whether the Swiss version of GVD exhibits in-sample predictive power for Swiss asset market returns.

Table 4 summarizes the results from the baseline regression of Swiss stock and bond market excess returns on GVD and its two components. Panel A of Table 4 shows that GVD exhibits forecast power for Swiss stock market returns at all of the forecast horizons. GVD describes $1.6 \%$ of the variation in 1-month ahead stock market returns and almost $14 \%$ at the 12-month horizon. Judged by the bootstrapped $p$ values, GVD's predictive power is statistically significant at conventional significance levels.

Examining the two components of GVD separately, it becomes apparent that $\mathrm{GVD}^{\text {new }}$ drives the predictive power for stock market returns. At short forecast horizons it even outperforms total GVD, which might be due to the fact that GVD ${ }^{\text {old }}$ does not forecast stock returns at all. The regression coefficient occasionally takes the wrong sign and is never significantly different from zero.

This picture changes for the assessment of GVD's predictive power for Swiss bond market returns. The regression estimates presented in panel B of Table 4 highlight that GVD does not forecast Swiss bond market returns at all. This finding is again driven by GVD ${ }^{\text {new }}$ - the dominant driver of variation in GVD- which appears to be unrelated to future bond market returns. By contrast, GVD $^{\text {old }}$ forecasts bond market returns 1-month ahead with an $R^{2}$ statistic of $1.7 \%$. However, it exhibits no 
Table 3 In-sample predictability of US GVD for stock returns

\begin{tabular}{|c|c|c|c|c|c|c|c|c|}
\hline \multicolumn{9}{|c|}{ Panel A: Predictability of US stock market excess returns } \\
\hline \multirow[b]{2}{*}{1980} & \multicolumn{2}{|l|}{$h=1$} & \multicolumn{2}{|l|}{$h=3$} & \multicolumn{2}{|l|}{$h=6$} & \multicolumn{2}{|l|}{$h=12$} \\
\hline & $\hat{\beta}$ & $R^{2}(\%)$ & $\hat{\beta}$ & $R^{2}(\%)$ & $\hat{\beta}$ & $R^{2}(\%)$ & $\hat{\beta}$ & $R^{2}(\%)$ \\
\hline & $0.42^{* *}$ & 0.94 & $0.52^{* * *}$ & 4.15 & $0.43^{* * *}$ & 5.13 & $0.35^{* *}$ & 6.47 \\
\hline ( $p$ value) & $(0.02)$ & & $(0.00)$ & & $(0.01)$ & & $(0.02)$ & \\
\hline 1990 & $0.41^{* *}$ & 1.00 & $0.46^{* *}$ & 3.49 & $0.40^{* * *}$ & 4.63 & $0.35^{* *}$ & 6.41 \\
\hline ( $p$ value) & $(0.04)$ & & $(0.01)$ & & $(0.02)$ & & $(0.04)$ & \\
\hline 1999 & 0.31 & 0.52 & $0.37^{*}$ & 2.02 & $0.36^{*}$ & 3.20 & 0.37 & 5.84 \\
\hline ( $p$ value) & $(0.16)$ & & $(0.08)$ & & $(0.08)$ & & $(0.12)$ & \\
\hline \multicolumn{9}{|c|}{ Panel B: Predictability of Swiss stock market excess returns } \\
\hline & $\hat{\beta}$ & $R^{2}(\%)$ & $\hat{\beta}$ & $R^{2}(\%)$ & $\hat{\beta}$ & $R^{2}(\%)$ & $\hat{\beta}$ & $R^{2}(\%)$ \\
\hline 1980 & -0.08 & 0.03 & 0.01 & 0.00 & 0.04 & 0.04 & 0.07 & 0.20 \\
\hline ( $p$ value) & $(0.62)$ & & $(0.47)$ & & $(0.25)$ & & $(0.35)$ & \\
\hline 1990 & -0.08 & 0.03 & -0.02 & 0.00 & 0.06 & 0.07 & 0.13 & 0.66 \\
\hline ( $p$ value) & $(0.57)$ & & $(0.50)$ & & $(0.37)$ & & $(0.28)$ & \\
\hline 1999 & 0.01 & 0.00 & 0.04 & 0.02 & 0.11 & 0.33 & 0.20 & 1.81 \\
\hline ( $p$ value) & $(0.49)$ & & $(0.43)$ & & $(0.33)$ & & $(0.23)$ & \\
\hline
\end{tabular}

Notes: This table presents OLS estimates from univariate regressions of $h$-month ahead US (panel A) or Swiss (panel B) stock market returns on the US version of GVD over different sample periods that all end in December 2017. The starting points of the different sample periods are January 1980 (row "1980"), January 1990 , and January 1999. The US GVD is z-standardized. We compute heteroskedasticity and autocorrelation robust $p$ values (in parentheses below the estimates) from a wild bootstrap procedure that tests the null hypothesis of $\hat{\beta}^{h}=0$ against the alternative that $\hat{\beta}^{h}>0$ because high values of the US GVD predict high excess returns. ${ }^{*}$,**, and ${ }^{* * *}$ indicate significance at the $10 \%, 5 \%$, and $1 \%$ level, respectively

Table 4 In-sample predictability of Swiss stock market and bond market excess returns using GVD or its components

\begin{tabular}{|c|c|c|c|c|c|c|c|c|}
\hline \multicolumn{9}{|c|}{ Panel A: Predictability of stock market excess returns } \\
\hline \multirow[b]{2}{*}{ Predictor } & \multicolumn{2}{|l|}{$h=1$} & \multicolumn{2}{|l|}{$h=3$} & \multicolumn{2}{|l|}{$h=6$} & \multicolumn{2}{|l|}{$h=12$} \\
\hline & $\hat{\beta}$ & $R^{2}(\%)$ & $\hat{\beta}$ & $R^{2}(\%)$ & $\hat{\beta}$ & $R^{2}(\%)$ & $\hat{\beta}$ & $R^{2}(\%)$ \\
\hline GVD & $0.50^{* *}$ & 1.61 & $0.48^{* *}$ & 3.46 & $0.59^{* *}$ & 8.72 & $0.57^{* *}$ & 13.88 \\
\hline ( $p$ value) & $(0.03)$ & & $(0.02)$ & & $(0.02)$ & & $(0.02)$ & \\
\hline GVD new & $0.55^{* *}$ & 1.92 & $0.60^{* *}$ & 5.33 & $0.61^{* * *}$ & 9.44 & $0.55^{* *}$ & 12.93 \\
\hline ( $p$ value) & $(0.03)$ & & $(0.02)$ & & $(0.00)$ & & $(0.01)$ & \\
\hline GVDold & -0.34 & 0.72 & -0.18 & 0.49 & -0.05 & 0.06 & 0.14 & 0.85 \\
\hline ( $p$ value) & $(0.84)$ & & $(0.73)$ & & $(0.53)$ & & $(0.37)$ & \\
\hline \multicolumn{9}{|c|}{ Panel B: Predictability of bond market excess returns } \\
\hline Predictor & $\hat{\beta}$ & $R^{2}(\%)$ & $\hat{\beta}$ & $R^{2}(\%)$ & $\hat{\beta}$ & $R^{2}(\%)$ & $\hat{\beta}$ & $R^{2}(\%)$ \\
\hline GVD & 0.02 & 0.05 & 0.03 & 0.35 & 0.04 & 0.88 & 0.04 & 1.56 \\
\hline ( $p$ value) & $(0.39)$ & & $(0.33)$ & & $(0.32)$ & & $(0.35)$ & \\
\hline$G V D^{\text {new }}$ & -0.02 & 0.07 & -0.01 & 0.05 & 0.02 & 0.29 & 0.03 & 0.71 \\
\hline ( $p$ value) & $(0.67)$ & & $(0.57)$ & & $(0.38)$ & & $(0.36)$ & \\
\hline GVDold & $0.12^{* *}$ & 1.68 & 0.07 & 1.63 & 0.03 & 0.38 & 0.01 & 0.22 \\
\hline ( $p$ value) & $(0.01)$ & & $(0.14)$ & & $(0.35)$ & & $(0.41)$ & \\
\hline
\end{tabular}

Notes: This table presents OLS estimates from univariate regressions of $h$-month ahead Swiss stock (panel A) and bond market (panel B) returns on GVD or one of its components (see Table 1 for a description of the variables). All variables are $z$-standardized. The sample period runs from January 1999 to December 2017 . We compute heteroskedasticity and autocorrelation robust $p$ values (in parentheses below the estimates) from a wild bootstrap procedure that tests the null hypothesis of $\hat{\beta}^{h}=0$ against the alternative that $\hat{\beta}^{h}>0$ because the regressors are defined in such a way that high values predict high excess returns. ${ }^{*}$, ${ }^{*}$, and ${ }^{* * *}$ indicate significance at the $10 \%, 5 \%$, and $1 \%$ level, respectively 
significant forecasting power at forecast horizons longer than 1 month.

These results are unchanged if we run multivariate regressions, i.e., regressions in which $\mathrm{GVD}^{\text {new }}$ and GVD $^{\text {old }}$ are simultaneously used as regressors, because of the low correlation between the two components of GVD. The results of these regressions are not reported but available upon request.

Taken together, these results suggest that the distinction between the two GVD components matters in the Swiss case. This finding stands in contrast to the US evidence which did not find significant differences between the forecast performances of GVD or its components.

\subsubsection{Swiss GVD versus standard US predictors}

Does the predictive power of GVD survive in the presence of global predictors of asset market returns? This is a pertinent question because the Swiss stock market is dominated by firms that generate their earnings from worldwide activities (Rasch 2015) and Swiss government bonds tend to be viewed as safe assets which are in high demand during periods of international crises (Nitschka 2016).

To assess this question, we run the in-sample forecast regression in Eq. (5) for excess returns on the Swiss stock market and use standard US predictors as stand-in for global predictive variables. The results of these regressions are summarized in Table 5 . Note that we perform only univariate regressions because of the high correlation between some of the US predictors (see Table 2).

The main results of this assessment are easily summarized. At short forecast horizons of 1 month and 3 months, the US stock market variance (svar) appears to be the best US predictor. High svar predicts low future Swiss stock market returns, and the $R^{2}$ statistics reach $3 \%$ and $6 \%$ at the 1-month and the 3-month forecast horizon. At longer forecast horizons, the US dividend yield $(d y)$ appears to perform best among the US predictors. It significantly predicts Swiss stock market returns at the 6-month and 12-months horizon with $R^{2}$ statistics of $7 \%$ and $13 \%$, respectively.

We use these results to evaluate the question of whether the predictive power of $\mathrm{GVD}^{\text {new }}$ survives in a multivariate forecast regression, i.e., in a regression in which we include the best US predictor for each forecast horizon (svar at 1-month and 3-month horizon and $d y$ at 6-month and 12-month horizon) as an additional regressor to $\mathrm{GVD}^{\text {new }}$. Panel B of Table 5 presents the results of this assessment. These results show that $\mathrm{GVD}^{\text {new }}$ exhibits predictive power for Swiss stock market returns that is

Table 5 In-sample predictability of Swiss stock market excess returns: the US predictors versus GVD

\begin{tabular}{|c|c|c|c|c|c|c|c|c|}
\hline \multicolumn{9}{|c|}{ Panel A: Predictive power of US predictors } \\
\hline & \multicolumn{2}{|l|}{$h=1$} & \multicolumn{2}{|l|}{$h=3$} & \multicolumn{2}{|l|}{$h=6$} & \multicolumn{2}{|l|}{$h=12$} \\
\hline Predictor & $\hat{\beta}$ & $R^{2}(\%)$ & $\hat{\beta}$ & $R^{2}(\%)$ & $\hat{\beta}$ & $R^{2}(\%)$ & $\hat{\beta}$ & $R^{2}(\%)$ \\
\hline$d p$ & 0.27 & 0.48 & 0.36 & 1.88 & 0.46 & 5.36 & $0.52^{*}$ & 11.52 \\
\hline ( $p$ value) & $(0.23)$ & & $(0.19)$ & & $(0.11)$ & & $(0.06)$ & \\
\hline$d y$ & 0.40 & 1.03 & 0.44 & 2.76 & $0.53^{*}$ & 6.92 & $0.55^{* *}$ & 13.03 \\
\hline ( $p$ value) & $(0.12)$ & & $(0.12)$ & & $(0.06)$ & & $(0.05)$ & \\
\hline$e p$ & 0.23 & 0.34 & 0.13 & 0.26 & 0.08 & 0.16 & 0.16 & 1.07 \\
\hline ( $p$ value) & $(0.32)$ & & $(0.42)$ & & $(0.45)$ & & $(0.38)$ & \\
\hline de & -0.07 & 0.03 & 0.05 & 0.04 & 0.14 & 0.52 & 0.10 & 0.45 \\
\hline ( $p$ value) & (0.52) & & $(0.43)$ & & $(0.35)$ & & $(0.36)$ & \\
\hline svar & $-0.67^{* * *}$ & 2.83 & $-0.66^{* * *}$ & 6.47 & -0.31 & 2.38 & 0.01 & 0.00 \\
\hline ( $p$ value) & $(0.00)$ & & $(0.00)$ & & $(0.25)$ & & $(0.45)$ & \\
\hline ntis & 0.17 & 0.19 & 0.25 & 0.91 & 0.24 & 1.38 & 0.21 & 1.88 \\
\hline ( $p$ value) & (0.35) & & $(0.32)$ & & $(0.36)$ & & $(0.37)$ & \\
\hline ts & -0.27 & 0.48 & -0.18 & 0.47 & -0.06 & 0.10 & 0.22 & 2.05 \\
\hline ( $p$ value) & (0.83) & & $(0.70)$ & & $(0.55)$ & & $(0.25)$ & \\
\hline ds & -0.41 & 1.06 & -0.23 & 0.80 & -0.00 & 0.00 & 0.15 & 0.96 \\
\hline ( $p$ value) & (0.78) & & $(0.60)$ & & $(0.48)$ & & $(0.32)$ & \\
\hline \multicolumn{9}{|c|}{ Panel B: marginal contribution of GVD new in the presence of best US predictor at each forecast horizon } \\
\hline & $\hat{\beta}$ & Partial $R^{2}(\%)$ & $\hat{\beta}$ & Partial $R^{2}(\%)$ & $\hat{\beta}$ & Partial $R^{2}(\%)$ & $\hat{\beta}$ & Partial $R^{2}(\%)$ \\
\hline GVDew & $0.54^{*}$ & 1.78 & $0.55^{* *}$ & 4.58 & $0.51^{* *}$ & 3.80 & $0.39^{*}$ & 4.31 \\
\hline ( $p$ value) & $(0.07)$ & & $(0.04)$ & & $(0.04)$ & & $(0.10)$ & \\
\hline
\end{tabular}

Notes: Panel A of this table presents OLS estimates from univariate regressions of $h$-month ahead Swiss stock market returns on each potential US predictor variable described in Tables 1 and 2 with the exception of US GVD. Panel B gives OLS estimates from regressions of $h$-month ahead Swiss stock market returns on GVDew and the best US predictor at each forecast horizon. These estimates show whether GVD new adds predictive power in the presence of the best US predictor. The sample period runs from January 1999 to December 2017. We compute heteroskedasticity and autocorrelation robust $t$-statistics (in parentheses below the estimates) from a wild bootstrap procedure that tests the null hypothesis of $\hat{\beta}^{h}=0$ against the alternative that $\hat{\beta}^{h}>0$ or $\hat{\beta}^{h}<0$ in the case of svar. ${ }^{*}$, ${ }^{* *}$, and ${ }^{* * *}$ indicate significance at the $10 \%, 5 \%$, and $1 \%$ level, respectively 
independent from the best US predictor. The regression coefficients of GVD ${ }^{\text {new }}$ are significant at all forecast horizons, and it additionally describes about $5 \%$ (according to the partial $R^{2}$ ) of the return variation.

We repeat this empirical analysis for Swiss bond market returns. The results of this assessment are summarized in Table 6. At the 1-month forecast horizon svar appears to predict Swiss bond returns best, but the forecast performance of the term spread is close. At longer forecast horizons, the US term spread clearly is the best and most significant predictor of Swiss bond market returns. The US term spread describes more than $30 \%$ of the variation in 12-month ahead returns on the Swiss bond market.

GVD ${ }^{\text {old }}$ exhibits forecast power for Swiss bond market returns at the 1-month horizon. Panel B of Table (6) shows that this forecast ability survives in the presence of svar. This finding also holds for the term spread as "control" variable in the regressions (not reported but available upon request). At longer forecast horizons, $\mathrm{GVD}^{\text {old }}$ does not add forecast power to the US term spread.

\subsection{Out-of-sample predictability}

Goyal and Welch (2008) argue that a predictor of asset returns should not only display in-sample predictive power but should also forecast asset returns out-of- sample. Many of the standard predictors of the US asset returns fail that test. There are notable exceptions. Short interest, loosely understood as an aggregate of the number of shares held short, explains the future US stock market returns significantly both in in-sample and in outof-sample forecast regressions (Rapach et al. 2016). The US version of GVD forecasts both stock market returns and bond market returns as well as variables that proxy the state of the economy in-sample and out-of-sample (Duarte and Kapadia 2017).

This section provides the results from assessments of the out-of-sample forecast ability of the Swiss versions of GVD and the standard US predictors for stock market returns and bond market returns. We therefore run the regression in Eq. (5) over an evaluation period to obtain forecasts of the $h$-period ahead stock and bond market returns from the estimates of $\alpha$ and $\beta$ for each of the predictor variables, i.e.,

$$
\hat{r}_{t, t+h}^{\text {stock,bond }}=\hat{\alpha}+\hat{\beta}^{h} x_{t}
$$

Then, we compute the out-of-sample $R^{2}$ statistic $\left(R_{\text {oos }}^{2}\right)$ proposed by (Campbell and Thompson 2008). This statistic obeys

Table 6 In-sample predictability of Swiss bond market excess returns

Panel A: Predictive power of US predictors

\begin{tabular}{|c|c|c|c|c|c|c|c|c|}
\hline \multirow{3}{*}{$\begin{array}{l}\text { Predictor } \\
d p\end{array}$} & \multicolumn{2}{|l|}{$h=1$} & \multicolumn{2}{|l|}{$h=3$} & \multicolumn{2}{|l|}{$h=6$} & \multicolumn{2}{|l|}{$h=12$} \\
\hline & $\hat{\beta}$ & $R^{2}(\%)$ & $\hat{\beta}$ & $R^{2}(\%)$ & $\hat{\beta}$ & $R^{2}(\%)$ & $\hat{\beta}$ & $R^{2}(\%)$ \\
\hline & $0.08^{*}$ & 0.87 & 0.06 & 1.39 & 0.05 & 1.32 & 0.03 & 0.95 \\
\hline ( $p$ value) & $(0.09)$ & & $(0.18)$ & & $(0.25)$ & & $(0.34)$ & \\
\hline $\begin{array}{l}d y \\
\text { ( } p \text { value) }\end{array}$ & $\begin{array}{l}0.06 \\
(0.16)\end{array}$ & 0.52 & $\begin{array}{l}0.05 \\
(0.24)\end{array}$ & 0.77 & $\begin{array}{l}0.04 \\
(0.31)\end{array}$ & 0.75 & $\begin{array}{l}0.02 \\
(0.38)\end{array}$ & 0.55 \\
\hline $\begin{array}{l}\text { ep } \\
\text { ( } p \text { value) }\end{array}$ & $\begin{array}{l}-0.03 \\
(0.70)\end{array}$ & 0.13 & $\begin{array}{l}-0.03 \\
(0.72)\end{array}$ & 0.40 & $\begin{array}{l}-0.05 \\
(0.78)\end{array}$ & 1.30 & $\begin{array}{l}-0.07 \\
(0.89)\end{array}$ & 5.28 \\
\hline $\begin{array}{l}\text { de } \\
\text { ( } p \text { value) }\end{array}$ & $\begin{array}{l}0.07 \\
(0.17)\end{array}$ & 0.54 & $\begin{array}{l}0.06 \\
(0.16)\end{array}$ & 1.19 & $\begin{array}{l}0.06 \\
(0.13)\end{array}$ & 2.29 & $\begin{array}{l}0.07 \\
(0.08)\end{array}$ & 5.93 \\
\hline $\begin{array}{l}\text { svar } \\
\text { ( } p \text { value) }\end{array}$ & $\begin{array}{l}0.19^{* * *} \\
(0.00)\end{array}$ & 4.72 & $\begin{array}{l}0.13^{* * *} \\
(0.00)\end{array}$ & 5.45 & $\begin{array}{l}0.07 \\
(0.02)\end{array}$ & 2.96 & $\begin{array}{l}0.05 \\
(0.07)\end{array}$ & 2.90 \\
\hline $\begin{array}{l}\text { ntis } \\
\text { ( } p \text { value) }\end{array}$ & $\begin{array}{l}0.01 \\
(0.43)\end{array}$ & 0.03 & $\begin{array}{l}0.02 \\
(0.41)\end{array}$ & 0.20 & $\begin{array}{l}0.01 \\
(0.48)\end{array}$ & 0.03 & $\begin{array}{l}-0.00 \\
(0.51)\end{array}$ & 0.00 \\
\hline $\begin{array}{l}\text { ts } \\
\text { ( } p \text { value) }\end{array}$ & $\begin{array}{l}0.18^{* * *} \\
(0.01)\end{array}$ & 3.95 & $\begin{array}{l}0.19^{* * *} \\
(0.01)\end{array}$ & 12.18 & $\begin{array}{l}0.21^{* *} \\
(0.01)\end{array}$ & 23.07 & $\begin{array}{l}0.17^{* *} \\
(0.01)\end{array}$ & 33.22 \\
\hline $\begin{array}{l}d s \\
\text { ( } p \text { value) }\end{array}$ & $\begin{array}{l}0.11^{*} \\
(0.06)\end{array}$ & 1.59 & $\begin{array}{l}0.09^{*} \\
(0.09)\end{array}$ & 2.42 & $\begin{array}{l}0.06 \\
(0.16)\end{array}$ & 2.20 & $\begin{array}{l}0.05 \\
(0.13)\end{array}$ & 2.96 \\
\hline \multicolumn{9}{|c|}{ Panel B: marginal contribution of GVD old in the presence of the best US predictor at each forecast horizon } \\
\hline & $\hat{\beta}$ & Partial $R^{2}(\%)$ & $\hat{\beta}$ & Partial $R^{2}(\%)$ & $\hat{\beta}$ & Partial $R^{2}(\%)$ & $\hat{\beta}$ & Partial $R^{2}(\%)$ \\
\hline $\begin{array}{l}\text { GVDold } \\
\text { ( } p \text { value) }\end{array}$ & $\begin{array}{l}0.10^{* *} \\
(0.03)\end{array}$ & 1.49 & $\begin{array}{l}0.06 \\
(0.23)\end{array}$ & 1.55 & $\begin{array}{l}0.01 \\
(0.46)\end{array}$ & 0.64 & $\begin{array}{l}0.01 \\
(0.50)\end{array}$ & 0.43 \\
\hline
\end{tabular}

Notes: This table presents OLS estimates from univariate regressions of $h$-month ahead Swiss stock market returns on each potential predictor variable described in Tables 1 and 2 with the exception of US GVD. Panel B gives OLS estimates from regressions of $h$-month ahead Swiss bond market returns on GVDold and the best US predictor at each forecast horizon. These estimates show whether GVD old adds predictive power in the presence of the best US predictor. The sample period runs from January 1999 to December 2017. We compute heteroskedasticity and autocorrelation robust $t$-statistics (in parentheses below the estimates) from a wild bootstrap procedure that tests the null hypothesis of $\hat{\beta}^{h}=0$ against the alternative that $\hat{\beta}^{h}>0$ or $\hat{\beta}^{h}<0$ in the case of svar. ${ }^{*}$,**, and ${ }^{* * *}$ indicate significance at the $10 \%, 5 \%$, and $1 \%$ level, respectively 


$$
R_{\mathrm{oos}}^{2}=1-\frac{\sum_{t=\mathrm{tOOS}}^{T}\left(r_{t}-\hat{r}_{t}\right)^{2}}{\sum_{t=\mathrm{tOOS}}^{T}\left(r_{t}-\bar{r}_{t}\right)^{2}}
$$

in which $\hat{r}$ is the predicted value of the excess returns from Eq. (6) and $\bar{r}_{t}$ is the historical mean of the respective return from the beginning of the sample until $T-1$. Following Rapach et al. (2016), we test the statistical significance of $R_{\text {oos }}^{2}$ using the Clark and West (2007) test. A positive $R_{\text {oos }}^{2}$ indicates that the mean squared forecast error from the predictions by one of the forecast variables under study is lower than predictions using only the historical mean return. We evaluate the out-of-sample predictive ability of the predictors for the forecast period starting in January 2008 (tOOS), i.e., the evaluation period for the forecasts runs from January 1999 to December 2007. Then, we expand the window monthly from tOOS to $T$ (December 2017).

\subsubsection{GVD and its components}

Compared with the results from the in-sample regressions, the evidence of GVD's forecast ability is considerably weaker. The test statistics of the out-of-sample regressions for stock and bond returns are summarized in Table 7. Panel A of Table 7 reveals that GVD exhibits marginal out-of-sample predictive power for Swiss stock market returns 12-months ahead. The $R_{\text {oos }}^{2}$ statistics are positive for all the other forecast horizons as well, but they are not significantly different from zero. Interestingly, GVD $^{\text {new }}$ exhibits no predictive power, even though it is mainly responsible for the in-sample predictive power of GVD.
Panel B of Table 7 shows that the out-of-sample evidence corroborates the in-sample result that $\mathrm{GVD}^{\text {old }}$ forecasts Swiss bond market returns one-month ahead. This is also true in the out-of-sample setting. The $R_{\text {oos }}^{2}$ statistic at this forecast horizon is $2.45 \%$ and significant at the $95 \%$ confidence level.

\subsubsection{US predictors}

The out-of-sample evidence of the US predictors' forecast abilities largely corroborates the in-sample results. Table 8 presents the results of this assessment. Panel A of this table gives the stock market results. Similar to the in-sample results, the US dividend yield forecasts Swiss stock market returns out-of-sample at forecast horizons of 6 months and 12-months. However, there is no evidence of out-of-sample predictability at the 1-month and 3 -month horizons. The in-sample predictive power of the US stock market variance (svar) does not hold out-ofsample.

Panel B of Table 8 shows that the US term spread forecasts Swiss bond market returns out-of-sample at all forecast horizons. This finding corroborates the main findings of the in-sample forecast regressions. The $R_{\text {oos }}^{2}$ statistic for the out-of-sample forecasts using the term spread increase from $4.2 \%$ at the 1 -month horizon to approximately $35 \%$ at the 12 -month forecast horizon.

\section{Implications for VAR-based decompositions of Swiss asset returns?}

One of the motivations of this study is the evidence that asset return dynamics in the US and Switzerland appear

Table 7 Out-of-sample predictability of Swiss stock and bond market excess returns

Stock market returns: $R_{\text {oos }}^{2}$ in \%
Predictor
GVD


Table 8 US variables and out-of-sample predictability of Swiss stock and bond market excess returns

\begin{tabular}{|c|c|c|c|c|}
\hline \multicolumn{5}{|c|}{ Panel A: stock market returns ( $R_{\text {oos }}^{2}$ in \%) } \\
\hline Predictor & $h=1$ & $h=3$ & $h=6$ & $h=12$ \\
\hline$d p$ & -1.54 & -7.71 & 3.84 & $39.94^{*}$ \\
\hline$d y$ & 0.26 & -3.80 & $11.39 * *$ & $42.97^{*}$ \\
\hline$e p$ & -12.97 & -51.18 & -110.92 & -125.23 \\
\hline de & -23.58 & -117.28 & -281.21 & -221.84 \\
\hline svar & 1.48 & 0.09 & -86.73 & -60.78 \\
\hline ntis & -4.51 & -17.89 & $-48.71^{*}$ & $-91.04^{*}$ \\
\hline ts & -1.90 & -5.84 & -6.79 & 5.11 \\
\hline ds & -10.95 & -82.37 & -313.15 & 237.55 \\
\hline \multicolumn{5}{|c|}{ Panel B: bond market returns ( $R_{\text {oos }}^{2}$ in \%) } \\
\hline predictor & $h=1$ & $h=3$ & $h=6$ & $h=12$ \\
\hline$d p$ & -2.23 & -9.52 & -6.33 & -12.03 \\
\hline$d y$ & -2.01 & -6.55 & -4.47 & -16.25 \\
\hline$e p$ & -3.00 & -6.68 & -11.86 & -26.72 \\
\hline de & -11.00 & -50.34 & -111.20 & -203.60 \\
\hline svar & 2.12 & -15.41 & -27.75 & -4.92 \\
\hline ntis & -0.83 & -2.77 & -8.27 & $-28.26^{* *}$ \\
\hline ts & $4.20^{* *}$ & $13.26^{* *}$ & $25.37^{* *}$ & $34.93^{* *}$ \\
\hline$d s$ & -0.17 & -66.00 & -128.17 & -81.62 \\
\hline
\end{tabular}

Notes: This table reports the out-of-sample $R^{2}$ statistic $\left(R_{\text {oos }}^{2}\right)$ proposed by (Campbell and Thompson 2008) from out-of-sample forecasts of Swiss stock market returns.

This statistic obeys $R_{\text {oos }}^{2}=1-\frac{\sum_{t=\text { toos }}^{T}\left(r_{t}-\hat{r}_{t}\right)^{2}}{\sum_{t=\text { toos }}^{T}\left(r_{t}-\vec{r}_{t}\right)^{2}}$ in which $\hat{r}$ is the predicted value of the stock market excess returns and $\bar{r}_{t}$ is the historical mean of the return from the beginning of the sample until $T-1$. We test the statistical significance of $R_{\text {oos }}^{2}$ using the Clark and West (2007) test. A positive $R_{\text {oos }}^{2}$ indicates that the mean squared forecast error from the predictions by one of the forecast variables under study is lower than the benchmark, i.e., is lower than predictions using only the historical mean return. We evaluate the out-of-sample predictive ability of the predictors for the forecast period starting in January 2008 (tOOS), i.e., the evaluation period for the forecasts runs from January 1999 to December 2007. Then, we expand the window monthly from tOOS to $T$ (December 2017). ${ }^{*}, * *$, and ${ }^{* * *}$ indicate significance at the $10 \%, 5 \%$, and $1 \%$ level, respectively. The predictor variables are described in Table 2

to reflect different underlying drivers. Nitschka (2014) and Rey (2004) highlight that the time variation in excess returns on both Swiss stock and Swiss bond markets predominantly reflects cash-flow news, i.e., dividend news in the case of stock market returns and long-term inflation news in the case of government bond returns. In this respect, Swiss stock markets appear to be representative of other European stock markets (Nitschka 2010). By contrast, time variation in the returns on the US stock and bond markets is primarily driven by discountrate/expected-return news (Campbell 1991; Campbell and Ammer 1993; Campbell and Vuolteenaho 2004).

These analyses are based on separate vector autoregressive models (VAR) for each country and for slightly differing sample periods of 30 or more years. The news components are derived from the parameters of the respective VAR systems and are dependent on the country-specific variables that are chosen to be included in the VAR analysis because one of the news components (cash-flow news in the case of stock markets and discountrate news in the case of bond markets) is obtained as a residual.

The main analysis of this paper has shown that GVD exhibits some predictive power for Swiss asset returns. Hence, GVD's additional predictive power could alter the conclusions drawn by Rey (2004) and Nitschka (2014). In addition, our main results highlight that US variables exhibit predictive power for Swiss asset returns as well. The news decompositions of asset returns should take this evidence into account and include the US predictors of Swiss asset returns into the VAR system.

\subsection{VAR-based decompositions of stock and bond returns: background}

To evaluate the impact of GVD in news decompositions of Swiss asset market returns, we repeat the VAR-based decompositions presented by Nitschka (2014) for our shorter sample period from January 1999 to December 2017. The baseline decomposition is based on the estimation of a vector autoregressive model (lag length 1month) of a system that includes the excess return on the Swiss stock market as its first element, then follow the short-term real interest rate, changes in the nominal short-term rate, the spread between yields on long-term Swiss government bonds and a short-rate and the log dividend-price ratio of the Swiss stock market. The first four elements of the VAR system are necessary to obtain the stock market and bond market news components. The stock market excess return news component can be directly obtained from the VAR because it is the first element of the VAR system. The bond market excess return news is a combination of news about short-term interest rate changes, and the term spread because news about future bond returns can be written as news about future bond yields ${ }^{4}$ (Campbell and Ammer 1993). The Appendix provides more details of the Campbell and Ammer (1993) framework.

The VAR system mentioned above is our baseline specification. We first augment it by including the US dividend yield and the US term spread as additional variables because these variables exhibited insample and out-of-sample predictive power for Swiss stock returns and bond market returns. Our third VAR specification adds GVD to the second VAR system to assess whether the general conclusions regarding the relative importance of the different news components change when taking GVD's additional predictive power into account. 


\subsection{VAR-based decompositions of Swiss stock and bond returns: results}

We run the VAR estimations for the sample period from January 1999 to December 2017. Table 9 summarizes the variance decompositions of Swiss stock market and bond market return news. Ninety-five percent of confidence intervals from bootstrapping the respective statistics are in parentheses.

The left panel of Table 9 displays the outcome of the three variants of the variance decompositions for stock market news. The right panel gives the corresponding results for bond market news. The different components of the variance decomposition are defined in such a way that they sum to one, and they take into account that the news components might be correlated with each other. The signs of the covariance terms follow from the fact that unexpected news about stock excess returns (NR) are defined as news about future cash-flows (NCF) minus news about future real interest rates (NRR) and minus news about future excess returns (NRX). News about unexpected bond excess returns (NBR) are defined as negative cash-flow news minus real interest rate news minus news of future bond excess returns. The Appendix provides the background and the details to derive these relationships between the different news components.

In a nutshell, we observe that in the sample period from January 1999 to December 2017, we cannot confirm that cash-flow news dominates variation in Swiss stock market returns when we take the predictive power of US variables into account. Moreover, we observe some differences between the specifications that include or exclude GVD from the news decompositions. However, the uncertainty surrounding the various statistics is so large that we cannot reject the hypothesis that these differences are insignificant. This finding is in line with Engsted et al. (2012) who argue that obtaining the stock market's cash-flow news as residual is robust to the inclusion or exclusion of specific predictive variables as long as some of the state variables have the potential to not only signal future returns but also future cash-flows. The dividendprice ratio or the dividend yield have to signal dividends or returns by construction. This line of argument explains why taking account of GVD in the return decompositions does not lead to material changes.

We observe little differences between the different VAR specifications when we examine the variation in the bond news components. The conclusion that cash-flow news are mainly responsible for variation in unexpected bond excess returns seems to hold across the different VAR specifications.

\section{Conclusions}

Stylized facts of asset return predictability are mainly based on US evidence. We have used Switzerland as an

Table 9 News decomposition based on VAR estimations

\begin{tabular}{|c|c|c|c|c|c|c|c|}
\hline & \multicolumn{3}{|c|}{ Stock market news } & & \multicolumn{3}{|c|}{ Bond market news } \\
\hline & $(\mathrm{l})$ & (II) & (II) & & (I) & (II) & (III) \\
\hline $\operatorname{var}(\mathrm{NCF})$ & 1.24 & 0.94 & 1.20 & $\operatorname{var}(\mathrm{NCF})$ & 1.99 & 2.02 & 2.25 \\
\hline$(95 \% \mathrm{Cl})$ & $(0.91,1.71)$ & $(0.58,1.11)$ & $(0.87,1.65)$ & $(95 \% \mathrm{Cl})$ & $(0.66,7.34)$ & $(0.79,8.20)$ & $(0.79,8.26)$ \\
\hline $\operatorname{var}(\mathrm{NRR})$ & 0.02 & 0.01 & 0.01 & $\operatorname{var}(\mathrm{NRR})$ & 0.00 & 0.00 & 0.00 \\
\hline$(95 \% \mathrm{Cl})$ & $(0.01,0.02)$ & $(0.01,0.01)$ & $(0.01,0.02)$ & $(95 \% \mathrm{Cl})$ & $(0.00,0.00)$ & $(0.00,0.00)$ & $(0.00,0.00)$ \\
\hline $\operatorname{var}(\mathrm{NRX})$ & 0.48 & 1.10 & 1.23 & $\operatorname{var}(\mathrm{NRX})$ & 0.54 & 0.58 & 0.63 \\
\hline$(95 \% \mathrm{Cl})$ & $(0.34,0.66)$ & $(0.81,1.54)$ & $(0.89,1.73)$ & $(95 \% \mathrm{Cl})$ & $(0.25,1.82)$ & $(0.26,1.80)$ & $(0.28,1.93)$ \\
\hline$-2 \operatorname{Cov}(N C F, N R R)$ & 0.11 & -0.00 & 0.01 & $2 \operatorname{Cov}(N C F, N R R)$ & 0.00 & 0.00 & 0.00 \\
\hline$(95 \% \mathrm{Cl})$ & $(0.07,0.16)$ & $(-0.03,0.03)$ & $(-0.03,0.04)$ & $(95 \% \mathrm{Cl})$ & $(0.00,0.00)$ & $(0.00,0.01)$ & $(0.00,0.01)$ \\
\hline$-2 \operatorname{Cov}(N C F, N R X)$ & -0.73 & -1.02 & -1.41 & $2 \operatorname{Cov}(N C F, N R X)$ & -1.53 & -1.86 & -1.88 \\
\hline$(95 \% \mathrm{Cl})$ & $(-1.04,-0.41)$ & $(-1.47,-0.64)$ & $(-2.01,-0.90)$ & $(95 \% \mathrm{Cl})$ & $(-2.27,-0.95)$ & $(-3.03,-1.09)$ & $(-2.77,-1.22)$ \\
\hline $2^{*} \operatorname{Cov}(N R R, N R X)$ & -0.11 & -0.03 & -0.04 & $2^{*} \operatorname{Cov}(N R R, N R X)$ & -0.00 & -0.00 & -0.00 \\
\hline$(95 \% \mathrm{Cl})$ & $(-0.14,-0.09)$ & $(-0.06,-0.01)$ & $(-0.07,-0.00)$ & $(95 \% \mathrm{Cl})$ & $(-0.00,-0.00)$ & $(-0.00,0.00)$ & $(-0.00,-0.00)$ \\
\hline
\end{tabular}

Notes: This table gives the variance decomposition of unexpected excess returns on the Swiss stock (left panel) and bond (right panel) markets into variances and covariances of the three components: news about cash-flows (NCF), real interest rates (NRR), and future excess returns (NRX). These statistics are normalized by the variance of the total stock market return news such that they sum to one. We provide the $95 \%$ confidence interval of the statistics after 1000 bootstrap simulations in parentheses. The baseline decomposition is based on the estimation of a vector autoregressive model (lag length 1 month) of VAR systems that always include the excess return on the Swiss stock market as its first element, then follow the short-term real interest rate, changes in the nominal short-term rate, the spread between yields on long-term Swiss government bonds, and a short-rate and the log dividend-price ratio of the Swiss stock market. Column (I) presents the estimates from this VAR system for the sample period from January 1999 to December 2017. Column (II) provides the corresponding results from estimating a VAR that additionally includes the US dividend yield and the US term spread as predictive variables. The sample period remains the same. Finally, column (III) in each panel displays the results when we add Swiss GVD to the US variables and the other Swiss variables 


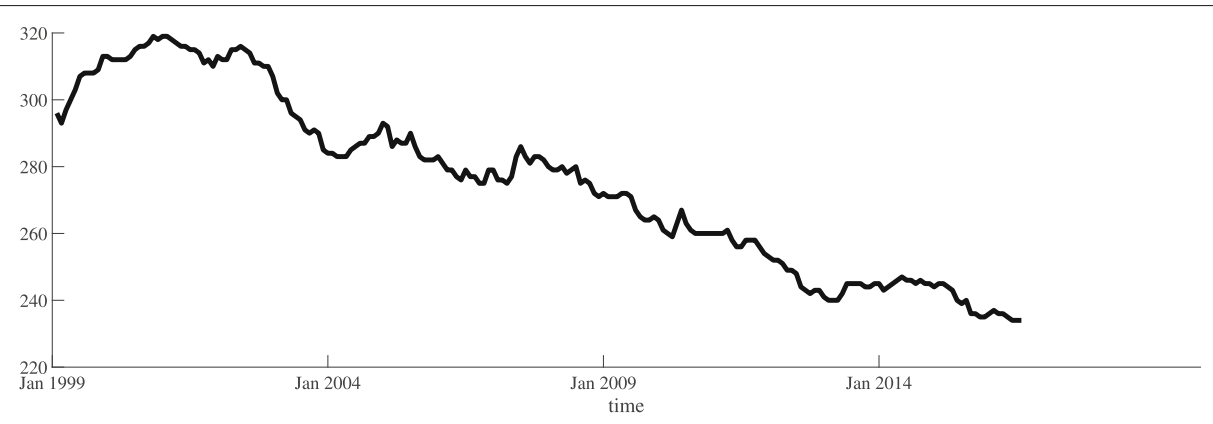

Fig. 1 Total number of firms listed on the Swiss stock exchange

example to stress that it cannot be taken for granted that empirical regularities observed in the US pertain to other economies as well. Our focus is on the Swiss version of a recently proposed predictor of the US stock and bond market returns. This predictor reflects changes in the weight of large firms in the aggregate Swiss stock market (GVD).

Our main results highlight that GVD exhibits some predictive power for Swiss stock and bond market returns even in the presence of global, i.e., US, predictors of asset returns. However, in contrast to the US evidence, the distinction between variation in GVD due to differences in the returns on existing capital between large firms and the aggregate market (GVD ${ }^{\text {old }}$ ) and differences in net new equity issuances between large firms and the aggregate market $\left(\mathrm{GVD}^{\text {new }}\right)$ is key to understanding its predictive power. It is GVD ${ }^{\text {new }}$ that predicts stock market returns in-sample. GVD ${ }^{\text {old }}$ forecasts bond market returns at the 1-month horizon but not at longer forecast horizons. The in-sample predictive power of GVD ${ }^{\text {new }}$ and GVD ${ }^{\text {old }}$ hold in the presence of US predictors, which means that they add information about time variation in Swiss stock and bond market returns.

\section{Appendix A: Swiss stock market and GVD \\ Swiss stock market: Institutional details and data}

The sample period for assessing asset return predictability in Switzerland is constrained by the availability of data. To construct GVD, we have to use Swiss stock market data that are only available from May 1996 onwards, when electronic asset trading was introduced in Switzerland. We have information about the total market capitalization of all shares of all Swiss non-financial and financial firms traded electronically on the Swiss exchange. When compiling the market capitalizations of listed Swiss firms, we take into account that different types of shares of one company could be traded at the same time. This is a typical feature of the Swiss and German stock markets. ${ }^{5}$ The total market capitalization of a firm is the sum of the value of the different share types.

In addition, this database provides us with a decomposition of changes in total market capitalization due to changes in the price of existing capital and net new equity capital. Thus, we are able to directly calculate the two components of GVD. Our sample period starts in January 1999 because of the 12-month horizon to construct GVD, which requires 2 full years of observations of net new capital activities.

From January 1999 to December 2017, the total number of firms listed on the Swiss stock exchange varies from approximately 230 to 319 . Figure 1 depicts the number of firms that make up the total market, $M$, over time. There has been a clear downward trend in the number of listed firms since the end of the technology firm boom around $2001 / 2002$.

However, despite the recent fall in the number of firms, the total market capitalization of the Swiss stock market has increased in recent years. Figure 2 presents the time series of the total market capitalization.

This finding suggests that small firms grew larger over the sample period. This is reflected in the descriptive statistics of GVD presented in Table 1 in the main body of the paper. The mean value of GVD is negative, which suggests that the total market capitalization of the total market (mainly composed of small firms) grew more than the market capitalization of the largest firms. The small firms on the Swiss stock market have become larger over our sample period.

Our baseline results presented in the main text rely on the formation of GVD using the 50 largest firms on the Swiss stock market. We opted for 50 firms to ensure that the number of largest firms relative to the total number of firms is relatively small. However, on average, the 50 largest firms comprise close to $90 \%$ of the total stock market capitalization. We also evaluated GVD versions using the 25 and the 75 largest firms in the sample for comparison. Even the 25 largest firms comprise more than $80 \%$ 


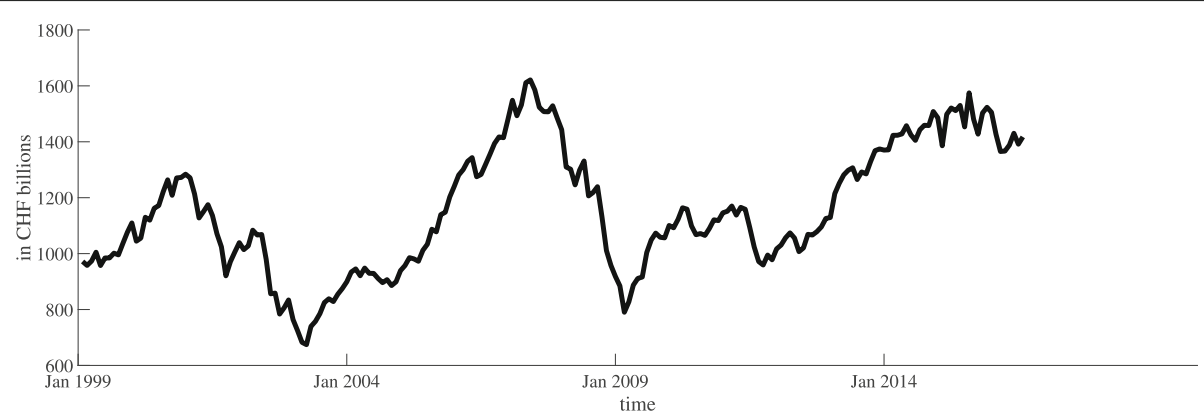

Fig. 2 Total Swiss stock market capitalization over time

of the total stock market capitalization. Figure 3 illustrates this point.

\section{Empirical results for alternative definitions of GVD}

Our baseline version of GVD focuses on the 50 largest firms of the Swiss stock market relative to the aggregate market, GVD ${ }^{50}$. These 50 largest firms comprise approximately $90 \%$ of the total market capitalization during our sample period. In robustness checks, we assess the performance of GVD constructed from the 25 and 75 largest firms on the Swiss stock market as well. The pairwise correlations between the three GVD series are high, varying between 0.93 and 0.99 .

Not surprisingly, the regression results for $\mathrm{GVD}^{25}$ and $\mathrm{GVD}^{75}$ are similar to the baseline evidence obtained with $\mathrm{GVD}^{50}$. Table 10 presents the in-sample forecast regression results for the two alternative definitions of GVD. These results suggest that the forecast ability of $\mathrm{GVD}^{25}$ for stock returns is less pronounced than that of $\mathrm{GVD}^{75}$ potentially reflecting the fact that three large firms account for between $40 \%$ and 50\% of the Swiss stock market's capitalization. The lower L, the more important valuation changes of these three firms are for the variation in GVD. As in the baseline results, bond market returns are not predictable by GVD.

Not shown, but available upon request, are the results for the components of GVD. The main conclusions remain unaltered irrespective of the number of firms to construct GVD. GVD ${ }^{\text {new }}$ exhibits in-sample predictability for stock market returns while GVD ${ }^{\text {old }}$ has some predictive power for bond market returns at the 1-month forecast horizon.

Out-of-sample regression results confirm the impression that the lower the number of firms used to calculate GVD, the lower its predictive power for Swiss stock market returns. In contrast to the baseline results, neither $\mathrm{GVD}^{75}$ nor $\mathrm{GVD}^{25}$ exhibit out-of-sample predictive power for Swiss stock market and bond market returns. Table 11 presents the detailed results.

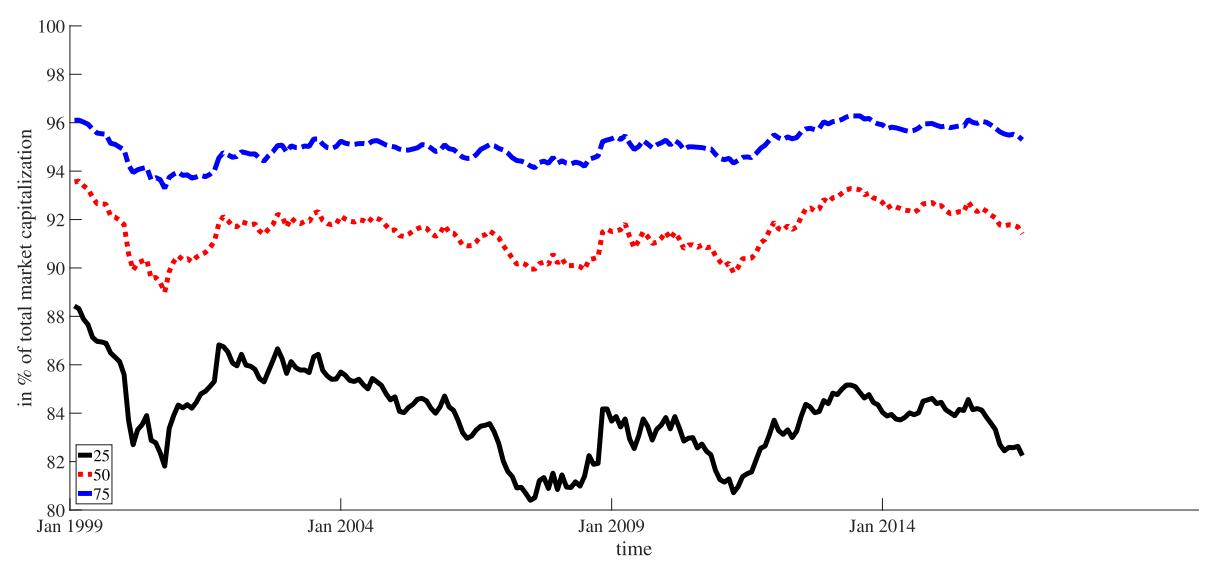

Fig. 3 Share of total market capitalization by L largest firms 
Table 10 In-sample predictability of stock and bond market excess returns

\begin{tabular}{|c|c|c|c|c|c|c|c|c|}
\hline \multicolumn{9}{|c|}{ Stock market return } \\
\hline \multirow[b]{2}{*}{ Predictor } & \multicolumn{2}{|l|}{$h=1$} & \multicolumn{2}{|l|}{$h=3$} & \multicolumn{2}{|l|}{$h=6$} & \multicolumn{2}{|l|}{$h=12$} \\
\hline & $\hat{\beta}$ & $R^{2}(\%)$ & $\hat{\beta}$ & $R^{2}(\%)$ & $\hat{\beta}$ & $R^{2}(\%)$ & $\hat{\beta}$ & $R^{2}(\%)$ \\
\hline \multirow[t]{2}{*}{$\mathrm{GVD}^{25}$} & 0.19 & 0.23 & 0.33 & 1.57 & $0.41^{*}$ & 4.20 & $0.48^{*}$ & 10.00 \\
\hline & $(0.82)$ & & $(1.55)$ & & $(2.06)$ & & $(2.66)$ & \\
\hline \multirow[t]{2}{*}{$\mathrm{GVD}^{75}$} & $0.40^{*}$ & 1.00 & $0.51^{* *}$ & 3.82 & $0.57^{* *}$ & 8.29 & $0.59^{* *}$ & 14.77 \\
\hline & $(1.56)$ & & $(2.40)$ & & $(3.28)$ & & $(4.02)$ & \\
\hline \multicolumn{9}{|c|}{ Bond market return } \\
\hline & $h=1$ & & $h=3$ & & $h=6$ & & $h=12$ & \\
\hline \multirow{3}{*}{$\begin{array}{l}\text { Predictor } \\
\text { GVD }^{25}\end{array}$} & $\hat{\beta}$ & $R^{2}(\%)$ & $\hat{\beta}$ & $R^{2}(\%)$ & $\hat{\beta}$ & $R^{2}(\%)$ & $\hat{\beta}$ & $R^{2}(\%)$ \\
\hline & 0.06 & 0.44 & 0.03 & 0.35 & 0.03 & 0.58 & 0.02 & 0.65 \\
\hline & $(0.89)$ & & $(0.53)$ & & $(0.63)$ & & $(0.52)$ & \\
\hline \multirow[t]{2}{*}{$\mathrm{GVD}^{75}$} & 0.02 & 0.03 & 0.02 & 0.09 & 0.03 & 0.64 & 0.03 & 0.94 \\
\hline & $(0.28)$ & & $(0.29)$ & & $(0.63)$ & & $(0.60)$ & \\
\hline
\end{tabular}

Notes: This table presents OLS estimates from univariate regressions of $h$-month ahead Swiss stock and bond market returns on GVD constructed with data of the 25 (GVD ${ }^{25}$ ) or $75\left(G D^{75}\right)$ largest firms in the Swiss stock market. The sample period runs from January 1999 to December 2017. We compute heteroskedasticity and autocorrelation robust $t$-statistics (in parentheses below the estimates) from a wild bootstrap procedure that tests the null hypothesis of $\hat{\beta}^{h}=0$ against the alternative that $\hat{\beta}^{h}>0$ because the regressors are defined in such a way that high values predict high excess returns. ${ }^{*},{ }^{*}$, and ${ }^{* * *}$ indicate significance at the $10 \%, 5 \%$, and $1 \%$ level, respectively

\section{Appendix B: VAR-based decomposition of stock and bond returns}

This section briefly highlights the economic background of the VAR-based decomposition of asset returns and additionally illustrates how the different news components can be backed out of the VAR. The notation and structure of this section follow closely Campbell and Ammer (1993) and Nitschka (2014).

Table 11 Out-of-sample predictive power for stock and bond market returns

\begin{tabular}{lllll}
\hline \multicolumn{5}{c}{ Stock market returns: $R_{\text {oos }}^{2}$ in \% } \\
Predictor & $h=1$ & $h=3$ & $h=6$ & $h=12$ \\
GVD $^{25}$ & -0.43 & -1.35 & -1.73 & -1.83 \\
GVD $^{75}$ & -0.08 & -0.49 & 0.03 & -2.40 \\
\multicolumn{1}{c}{ Bond market returns: $R_{\text {oos }}^{2}$ in \% } & & \\
Predictor & $h=1$ & $h=3$ & $h=6$ & $h=12$ \\
GVD $^{25}$ & 0.27 & -0.81 & -1.38 & -3.39 \\
GVD $^{75}$ & -0.27 & $-1.18^{*}$ & -3.67 & $-10.17^{*}$ \\
\hline
\end{tabular}

Notes: This table reports the out-of-sample $R^{2}$ statistic $\left(R_{\text {oos }}^{2}\right.$ ) proposed by (Campbell and Thompson 2008) from out-of-sample forecasts of Swiss stock market returns. This statistic obeys $R_{\text {Oos }}^{2}=1-\frac{\sum_{t=1005}^{T}\left(r_{t}-\hat{T}_{t}\right)^{2}}{\sum_{t=t \text { tos }}^{\prime}\left(r_{t}-T_{t_{t}}\right)^{2}}$ in which $\hat{r}$ is the predicted value of the stock market excess returns and $\bar{r}_{+}$is the historical mean of the return from the beginning of the sample until $T-1$. We test the statistical significance of $R_{\text {oos }}^{2}$ using the Clark and West (2007) test. A positive $R_{\text {oos }}^{2}$ indicates that the mean squared forecast error from the predictions by one of the forecast variables under study is lower than the benchmark, i.e., lower than predictions using only the historical mean return. We evaluate the out-of-sample predictive ability of the predictors for the forecast period starting in January 2008 (tOOS), i.e., the evaluation period for the forecasts runs from January 1999 to December 2007. Then, we expand the window monthly from tOOS to $T$. ${ }^{*},{ }^{* *}$, and ${ }^{* * *}$ indicate significance at the $10 \%, 5 \%$, and $1 \%$ level, respectively

\section{Unexpected asset returns and their news components}

The decomposition of asset returns highlighted in the main body of this paper is based on a dynamic accounting identity that links asset returns to expected cash-flows and discount rates (Campbell and Shiller 1988; Campbell 1991). This framework is applicable to stock and bond returns (Campbell and Ammer 1993; Shiller and Beltratti 1992).

Campbell and Shiller (1988) start the derivation of their framework from the two-period version of the present value model that links current stock prices to dividends and returns, i.e.,

$$
1+r_{t+1}=\frac{P_{t+1}+D_{t+1}}{P_{t}}
$$

with $r$, the net return on the stock, $P$, the stock price excluding dividends, and $D$, denoting dividends. Equation (8) implies that if stock prices and dividends are non-stationary, then returns should be stationary. However, stock returns vary at business cycle frequencies as risk aversion varies over the business cycle. To allow for time variation in returns, Campbell and Shiller (1988) propose a log-linear approximation of Eq. (8) around the mean dividend-price ratio. This approximation yields

$$
r_{t+1} \approx k+\rho p_{t+1}+(1-\rho) d_{t+1}-p_{t}
$$

where lower-case letters denote logarithms of the variables. The letter $k$ summarizes all constant terms following from the Taylor expansion, and $\rho=1 / 1+(\exp (d-p))$ is a weight that is obtained in the course of the loglinearization. This weight depends on the long-run mean of the $\log$ dividend-price ratio, $\mathrm{d}-\mathrm{p}$, around which Eq. (8) 
is linearized. This weight is slightly lower than unity. A representation of unexpected stock return movements can be obtained from rearranging Eq. (9) for the stock price, $p_{t} \approx k+\rho p_{t+1}+(1-\rho) d_{t+1}-r_{t+1}$ and then expanding this equation to the infinite horizon. This expansion relies on imposing the condition that discounted stock prices cannot grow forever, $\lim _{j \rightarrow \infty} \rho^{j} p_{t+j}=0$, and taking expectations on both sides of the equation such that

$$
p_{t}=\frac{k}{1-\rho}+E_{t}\left[\sum_{j=0}^{\infty} \rho^{j}\left((1-\rho) d_{t+1+j}-r_{t+1+j}\right)\right]
$$

with $E$ the expectation operator conditional on information at time $t$. Substituting Eq. (10) into Eq. (9), Campbell (1991) highlights that unexpected changes of stock returns either reflect news (revisions in expectations) of dividend growth or future discount rates, i.e.,

$$
r_{t+1}-E_{t} r_{t+1}=\left(E_{t+1}-E_{t}\right) \sum_{j=0}^{\infty} \rho^{j} \Delta d_{t+1+j}-\left(E_{t+1}-E_{t}\right) \sum_{j=0}^{\infty} \rho^{j} r_{t+1+j}
$$

Campbell and Ammer (1993) study excess returns, i.e., stock returns in excess of a short-term debt rate. In addition, they assume that the discount rate, $r$, is the sum of short-term real interest rates, $r r$, and a risk premium term, $r x$. Unexpected stock excess returns then obey

$$
\begin{aligned}
& r x_{t+1}-E_{t} r x_{t+1}=\left(E_{t+1}-E_{t}\right) \\
& \left\{\sum_{j=0}^{\infty} \rho^{j} \Delta d_{t+1+j}-\sum_{j=0}^{\infty} \rho^{j} r r_{t+1+j}-\sum_{j=1}^{\infty} \rho^{j} r x_{t+1+j}\right\}
\end{aligned}
$$

For notational convenience, Eq. (12) can be rewritten as

$$
\mathrm{NR}_{t+1}=\mathrm{NCF}_{t+1}-\mathrm{NRR}_{t+1}-\mathrm{NRX}_{t+1}
$$

with $\mathrm{NR}_{t+1} \equiv r x_{t+1}-E_{t} r x_{t+1}$, the unexpected stock market excess return; $\mathrm{NCF}_{t+1} \equiv\left(E_{t+1}-\right.$ $\left.E_{t}\right) \sum_{j=0}^{\infty} \rho^{j} \Delta d_{t+1+j}$, the news of future cash-flows (dividends); $\mathrm{NRR}_{t+1} \equiv\left(E_{t+1}-E_{t}\right) \sum_{j=0}^{\infty} \rho^{j} r r_{t+1+j}$, the news of the real interest rate; and finally, $\mathrm{NRX}_{t+1} \equiv\left(E_{t+1}-\right.$ $\left.E_{t}\right) \sum_{j=1}^{\infty} \rho^{j} r x_{t+1+j}$, the news of future excess returns which can be interpreted as proxy of expected risk premia. Following from this accounting identity a positive surprise movement in the excess stock market return is associated with positive dividend news, lower than expected real interest rates or lower than expected future excess returns or an arbitrary combination.

A similar decomposition as the one for stock excess returns applies to bond excess returns. Define the real, log bond return in excess of the short-term rate as

$$
b r x_{t+1}^{N} \equiv b_{t+1}^{N}-\pi_{t+1}-r r_{t+1}
$$

in which $b_{t+1}^{N} \equiv p_{t+1}^{N-1}-p_{t}^{N}$ is the log nominal oneperiod holding return on a N-period zero-coupon bond with nominal price, $p$. Inflation is denoted by $\pi$ and $r r$ represents the short-term real rate. Campbell and Ammer (1993) show that the unexpected bond excess return for a bond with maturity $N$ held from $t$ to $t+1$ (at which it becomes a $N-1$ period bond) obeys

$$
\begin{aligned}
& b r x_{t+1}^{N}-E_{t} b r x_{t+1}^{N}=\left(E_{t+1}-E_{t}\right) \\
& \left\{-\sum_{i=1}^{N-1} \pi_{t+1+i}-\sum_{i=1}^{N-1} r r_{t+1+i}-\sum_{i=1}^{N-1} b r x_{t+1+i}^{N-1}\right\}
\end{aligned}
$$

or in more compact notation

$$
\mathrm{NBR}_{t+1}=-\mathrm{NBCF}_{t+1}-\mathrm{NBRR}_{t+1}-\mathrm{NBRX}_{t+1}
$$

with $\mathrm{NBR}_{t+1} \equiv b r x_{t+1}^{N}-E_{t} b r x_{t+1}^{N}$, the unexpected excess return on the $n$-period, zero-coupon bond; $\mathrm{NBCF}_{t+1} \equiv\left(E_{t+1}-E_{t}\right) \sum_{i=1}^{N-1} \pi_{t+1+i}$, the cash-flow, i.e., inflation, news component; $\mathrm{NBRR}_{t+1} \equiv\left(E_{t+1}-\right.$ $\left.E_{t}\right) \sum_{i=1}^{N-1} r r_{t+1+i}$, the real interest rate news over the lifetime of the bond; and $\operatorname{NBRX}_{t+1} \equiv\left(E_{t+1}\right.$ $\left.E_{t}\right) \sum_{i=1}^{N-1} b r x_{t+1+i}^{N-1}$, the news about bond excess returns. A positive, unexpected bond excess return hence reflects an unexpected decline in inflation over the maturity of the bond, lower than the expected real interest rates or lower than the expected bond excess returns. Inflation corresponds to cash-flows because the bond price at the maturity date is fixed in nominal terms. Even when expected real interest rates or excess returns stay constant, the expected real payoff of the bond could vary because of changes in inflation over the lifetime of the bond.

\section{VAR-based decomposition of unexpected asset returns}

The state vector of the VAR contains the stock excess return as its first element and then follows the short-term, ex post measured, real interest rate, the change in the short-term nominal interest rate, and the spread between a long-term government bond yield and the short-term interest rate. These four elements are necessary to back out the different stock and bond excess return news components. Other elements should be able to predict future returns. The state vector should also include one variable that could predict both future returns or future cash-flows on the stock market because stocks' cash-flow news are obtained as residual from the other directly estimated news components (Engsted et al. 2012). Its importance could thus be overstated if the VAR system includes relatively poor predictors of future stock returns.

For notational convenience, consider a first-order VAR:

$$
z_{t+1}=\Gamma z_{t}+u_{t+1}
$$


in which $\Gamma$ is the matrix of VAR coefficients and $u$ denotes the error terms. Further define the vectors $e 1$ to $e 4$ to pick out different elements of the state vector. The first element in $e 1$ is one and all other elements are zero, and the second element in $e 2$ is one and all other elements zero and analogously for the other vectors $e 3$ and $e 4$. The news of the stock excess return can be directly obtained from Eq. (17) as $\mathrm{NR}_{t+1}=e 1^{\prime} u_{t+1}$ because the stock excess return is the first element of the state vector. News of the bond excess return can be derived from news of the short-term interest rate and news of the yield spread, i.e., $\mathrm{NBR}_{t+1}=-(n-1)\left(e 3^{\prime}+e 4^{\prime}\right) u_{t+1}$, thus exploiting that excess return news can equivalently be written as news of future bond yields. This latter news can again be written as the sum of news of changes in the short rate and the term yield spread because the lagged short-term interest rate is known at time $t$. Innovations in the change of the short-term interest rate thus reflect innovations in the level of the short-term interest rate (Campbell and Ammer 1993). The other news components are derived from (17) by using the VAR estimates to compute revisions in (longhorizon) expectations as $\left(E_{t+1}-E_{t}\right) z_{t+1+j}=\Gamma^{j} u_{t+1}$. In both stock and bond excess return decompositions two of the three different news components can be directly computed from the VAR estimates such that the third component has to be obtained as a residual.

The three news components of the stock market excess return are obtained in the following way. News of future expected stock market excess returns can be directly derived from the VAR estimates as

$$
\mathrm{NRX}_{t+1}=e 1^{\prime} \sum_{j=1}^{\infty} \rho^{j} \Gamma^{j} u_{t+1}=e 1^{\prime} \rho \Gamma(I-\rho \Gamma)^{-1} u_{t+1}
$$

and news of future real interest rates obey

$$
\mathrm{NRR}_{t+1}=e 2^{\prime} \sum_{j=0}^{\infty} \rho^{j} \Gamma^{j} u_{t+1}=e 2^{\prime}(I-\rho \Gamma)^{-1} u_{t+1}
$$

The news of future cash-flows of the stock market excess return is then obtained as residual, i.e.,

$$
\mathrm{NCF}_{t+1}=\mathrm{NR}_{t+1}+\mathrm{NRX}_{t+1}+\mathrm{NRR}_{t+1}
$$

The VAR estimates allow us to extract news components for bond excess returns too. From the VAR estimates, we can directly derive the news about real interest rates over the lifetime of the bond as

$$
\mathrm{NBRR}_{t+1}=e 2^{\prime} \sum_{i=1}^{n-1} \Gamma^{j} u_{t+1}=e 2^{\prime}(I-\Gamma)^{-1}\left(\Gamma-\Gamma^{n}\right) u_{t+1}
$$

(16) and cash-flow news (inflation news) as

$$
\begin{aligned}
\mathrm{NBCF}_{t+1} & =-\mathrm{NBRR}+e 3^{\prime}\left\{(I-\Gamma)^{-1}[(n-1) I\right. \\
& \left.+(I-\Gamma)^{-1}\left(\Gamma^{n}-\Gamma\right]\right\} u_{t+1}
\end{aligned}
$$

(17) such that news of future bond excess returns is obtained as the residual:

$$
\mathrm{NBRX}_{t+1}=-\mathrm{NBR}_{t+1}-\mathrm{NBRR}_{t+1}-\mathrm{NBCF}_{t+1}
$$

Since directly estimating the excess return news would require to take the shrinking maturity of the bond into account, we have to obtain that news component as the residual (Campbell and Ammer 1993; Engsted et al. 2012).

\section{Endnotes}

${ }^{1}$ Slegers (2014) examined the forecast ability of GVD (and its components) for France, Germany, Italy, and UK but did not find any sign of predictive ability. However, Slegers (2014) has to employ a short cut to calculate GVD $^{\text {new }}$. By contrast, we have high quality and detailed information about the data that is necessary to compute GVD $^{\text {new }}$. This difference in the data quality is the most likely explanation of the differences in our assessments of GVD's forecast performance, because the results in Nitschka (2010) suggest that the stock markets of Germany and also France and Italy are primarily driven by cash-flow news and thus similar to the Swiss stock market that we examine.

${ }^{2}$ Nestlé, Novartis, and Roche

${ }^{3}$ We are grateful to David Rapach for making the MATLAB code for these tests available on his website.

${ }^{4}$ The yield is just a convenient way to think of bond prices. The $\log$ yield of a bond with maturity $\mathrm{N}\left(y^{N}\right)$ is defined as $y^{N}=-\frac{1}{N} p^{N}$ in which $p$ denotes the log of the bond price. Bond returns (loosely speaking: changes in bond prices) are thus closely linked to yields.

${ }^{5}$ There are two broad categories of shares that grant voting rights to shareholders. Among these shares, one can distinguish shares that inform the firm about the name of the shareholder (in German: "Namensaktien") and shares that inform the firm only about the depository institutions at which the shares are held (in German: "Inhaberaktien"). In addition, we take into account "Partizipationsscheine," which are shares that do not grant any voting rights to shareholders. Many firms in our sample use at least two of the three different types of shares at the same time. 


\section{Abbreviations}

CHF: Swiss franc exchange rate; de: Logarithmic payout ratio; dp: Logarithmic dividend-price ratio; ds: Default spread; dy: Dividend yield; ep: Logarithmic earnings-price ratio; GVD: Changes of large firms' stock market capitalization relative to the changes in the aggregate stock market capitalization ("Goliath versus David"); NNC: Net new capital; ntis: Net equity expansion; SNB: Swiss National Bank; svar: Stock market variance; ts: Term spread

\section{Acknowledgements}

Substantial parts of this paper were written when David R. Haab was at the Swiss National Bank. The paper benefited from comments and suggestions by Cedric Tille (the editor), two anonymous referees of this journal, two anonymous referees of the SNB working paper series, Tjeerd M. Boonman, Richard Stehle, Adrien Verdelhan, and participants at the SSES Annual Meeting 2017 (Lausanne), the EEFS Annual Conference 2017 (Ljubljana), and the SNB Brown Bag workshop. Earlier versions of this paper circulated under the titles "Predicting returns on asset markets of a small, open economy and the influence of global risks" (SNB Working Paper 2017-14) and "What Goliaths and Davids among Swiss firms tell us about expected asset returns and the state of the economy." Moreover, we gratefully acknowledge that David Rapach made his MATLAB code for various tests of stock return predictability publicly available and that Nishad Kapadia provided us with the original US GVD data. Any errors and omissions are our own. The views, opinions, findings, and conclusions or recommendations expressed in this paper are strictly those of the authors. They do not necessarily reflect the views of the Swiss National Bank or the University of Zurich. Neither the Swiss National Bank nor the University of Zurich takes responsibility for any errors or omissions in, or for the correctness of, the information contained in this paper.

\section{Authors' contributions}

Both authors read and approved the final manuscript.

\section{Authors' information}

Not applicable.

\section{Funding}

Not applicable.

\section{Availability of data and materials}

Data available on corresponding author's website.

\section{Competing interests}

The authors declare that they have no competing interests.

\section{Author details}

${ }^{1}$ University of Zürich, Zürich, Switzerland. ${ }^{2}$ Swiss National Bank, Börsenstrasse 15, 8022 Zürich, Switzerland.

Received: 8 May 2018 Accepted: 20 June 2019

Published online: 09 December 2019

\section{References}

Ang, A., \& Bekaert, B. (2007). Stock return predictability: Is it there? Review of Financial Studies, 20, 651-707.

Bernanke, B., \& Gertler, M. (1989). Agency costs, net worth and business cycle fluctuations. American Economic Review, 79, 14-31.

Boudoukh, J., Richardson, M., Whitelaw, R.F. (2008). The myth of long-horizon predictability. Review of Financial Studies, 21, 1577-1605.

Campbell, J.Y. (1991). A variance decomposition for stock returns. Economic Journal, 101, 157-179.

Campbell, J.Y., \& Ammer, J. (1993). What moves the stock and bond markets? A variance decomposition for long-term asset returns. Journal of Finance, 48, $3-37$.

Campbell, J.Y., \& Shiller, R.J. (1988). The Dividend Price Ratio and Expectations of Future Dividends and Discount Factors. Review of Financial Studies, 1 , $195-227$.

Campbell, J.Y., \& Thompson, S.B. (2008). Predicting excess returns out of sample: Can anything beat the historical average? Review of Financial Studies, 21, 1509-1521.

Campbell, J.Y., \& Vuolteenaho, T. (2004). Bad beta, good beta. American Economic Review, 94, 1249-1275.
Clark, E.E., \& West, K.D. (2007). Approximately normal tests for equal predictive accuracy in nested models. Journal of Econometrics, 105, 85-110.

Cochrane, J.H. (2008). The dog that did not bark: A defense of return predictability. Review of Financial Studies, 21, 1533-1575.

Covas, F., \& Den Haan, W.J. (2011). The cyclical behavior of debt and equity finance. American Economic Review, 101, 877-899.

Duarte, J., \& Kapadia, N. (2017). Davids, Goliaths and Business Cycles. Journal of Financial and Quantitative Analysis, 52, 2429-2460.

Engsted, T., \& Pedersen, T.Q. (2010). The dividend-price ratio does predict dividend growth: International evidence. Journal of Empirical Finance, 17 585-605.

Engsted, T., Pedersen, T.Q., Tanggaard, C. (2012). Pitfalls in VAR based return decompositions: A clarification. Journal of Banking and Finance, 36, 1255-1265.

Ferson, W.E., Sarkissian, S., Simin, T. (2003). Spurious regressions in financial economics. Journal of Finance, 62, 1393-1414.

Gertler, M., \& Gilchrist, S. (1994). Monetary policy, business cycles, and the behaviour of small manufacturing firms. Quarterly Journal of Economics, 109, 309-340.

Goyal, A., \& Welch, I. (2008). A comprehensive look at the empirical performance of equity premium prediction. Review of Financial Studies, 21, 1455-1508.

Hodrick, R. (1992). Dividend yields and expected stock returns: Alternative procedures for inference and measurement. Review of Financial Studies, 5, 357-386.

Inoue, A., \& Kilian, L. (2005). In-sample or out-of-sample tests of predictability: Which one should we use? Econometric Reviews, 23, 371-402.

Kiyotaki, N., \& Moore, J. (1997). Credit Cycles. Journal of Political Economy, 105, $211-248$.

Nitschka, T. (2010). Cashflow news, the value premium and an asset pricing view on European stock market integration. Journal of International Money and Finance, 29, 1406-1423.

Nitschka, T. (2014). What news drive variation in Swiss and US bond and stock excess returns? Swiss Journal of Economics and Statistics, 150, 89-118.

Nitschka, T. (2016). Risk premia on Swiss government bonds and sectoral stock indexes during international crises. Aussenwirtschaft, 67, 51-67.

Perez-Quiros, G., \& Timmermann, A. (2000). Firm size and cyclical variations in stock returns. Journal of Finance, 55, 1229-1262.

Rangvid, J., Schmeling, M., Schrimpf, A. (2014). Dividend predictability around the world. Journal of Financial and Quantitative Analysis, 49, 1255-1277.

Rapach, D.E., Ringgenberg, M.C., Zhou, G. (2016). Short interest and aggregate stock returns. Journal of Financial Economics, 121, 46-65.

Rasch, M. (2015). Globalisierung der Unternehmen. http://www.nzz.ch/ finanzen/aktien/so-unschweizerisch-sind-die-smi-konzerne-1.18630520. Neue Zürcher Zeitung: So unschweizerisch sind die SMI-Konzerne.

Rey, D. (2004). A variance decomposition for Swiss stock market returns. University of Basel, WWZ/Department of Finance, Working Paper No.7/04.

Slegers, M. (2014). Predictability properties of the Goliath versus David variable for European Asset Returns, Netspar MSc Thesis, (pp. 2014-063).

Shiller, R.J., \& Beltratti, A.E. (1992). Stock prices and bond yields: Can their comovements be explained in terms of present value models? Journal of Monetary Economics, 30, 25-46.

Stambaugh, R.F. (1999). Predictive regressions. Journal of Financial Economics, $54,375-421$.

\section{Publisher's Note}

Springer Nature remains neutral with regard to jurisdictional claims in published maps and institutional affiliations. 